\title{
Thinking Outside Conventional Aerospace and Defense Technical Publications Using Standard Generalized Markup Language (SGML)
}

\author{
S. Santhosh Baboo ${ }^{1}$ and Nikhil Lobo ${ }^{*}, 2$

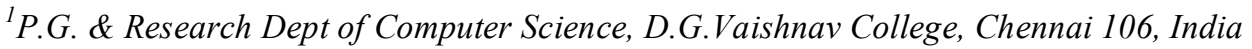 \\ ${ }^{2}$ Bharathiar University, Coimbatore, Tamil Nadu, India
}

\begin{abstract}
In Aerospace and Defense, documentation is of a very large size, highly structured and needs constant updating. Managing this documentation has been a constant challenge to this industry. Moreover accuracy of data is a critical aspect of constant worry to publication managers.

At present, documentation is being created using traditional publishing software resulting in wastage of time and effort. Time is spent in formatting documents instead of creation of content. Each time a document is created or updated formatting has to be applied manually. Preparing documents for print or web requires complete reformatting. Content is not structured across similar types of publications resulting in no consistency.

Standard Generalized Mark-up Language (SGML) allows a document to be broken up into modules allowing reusability. SGML enforces content to be developed in a structured manner maintaining consistency across publications. This structured approach is achieved using a Document Type Definition (DTD). Separation of content from formatting is achieved using Format Output Specification Instance (FOSI).
\end{abstract}

Keywords: Standard generalized mark-up language, document type definition, and format output specification instance, technical publications.

\section{INTRODUCTION}

The aircraft and defense industry is faced continuously with a challenge to manage information and publishing requirements. The documents particularly in this industry are generally of a large size, highly structured and regularly updated. Since this information is used to train aircraft personnel in it's description, maintenance, training and operation, it is mandatory to ensure that this information is easily available and technically correct. A single aircraft maintenance manual can even exceed 40,000 pages. Content is constantly being revised to represent new configurations of aircrafts, enhancements in technical procedures and changes in engineering practices. This requires documents to updated and reissued every 120 days. Moreover this information needs to be delivered to a wide range of customers in different output forms like paper, microfilm, digital interchange formats and CD-ROM.

Since the advent of desktop publishing tools and word processing software for creation of technical publications, processes have been labor intensive resulting in long publication development life cycles. Each time a document is created or updated formatting has to be applied manually. Moreover preparing documents for print or web requires complete reformatting. There is a tendency for authors to recreate content instead of reusing it resulting in an increase in both time and cost. This results in authors updating and

*Address correspondence to this author at the Bharathiar University, Coimbatore, Tamil Nadu, India; E-mail: nikhillobo@baehal.com reformatting every instance the information is repeated. This imposes a burden on authors and prevents them from frequent updating of information. Moreover inconsistencies in structure of information across similar documents make the content difficult for readers to understand and update.

Following are the objectives to be achieved using SGML in aerospace and defense publications:

- Cut redundant editing by $80 \%$ or more

- $\quad$ Reduced production time by $60 \%$ or more

- Increased output by $40 \%$ or more and

- Lowered error rates from one every 33 pages to one every 400 or more pages

\section{STANDARD GENERALIZED MARKUP LANGUAGE}

The word "markup" was originally handwritten instructions on an author's manuscript to describe the appearance of text on a printed page like a wavy underline to indicate boldface or special symbols to indicate passages to be omitted or printed in a particular font [1]. With the introduction of computers these markup instructions were embedded in the text of the document itself by a process known as "specific markup". These markup instructions were very obscure characters to distinguish them from the body text. These had to be entered manually and were very time consuming. Moreover every new phototypesetting system had its own proprietary markup language thereby binding consumers to a particular language and vendor. 
The Graphics Communications Association (GCA) in the 1980 's set out to define a standard markup language known as 'GenCode'. However, the GCA was faced with the problem of building a tag set that would address the needs of all phototypesetting systems. As the GCA was working on this problem, an ANSI committee was creating a standard called Generalized Markup Language (GML). In this standard a document was represented as a hierarchical tree of different elements having each formatted in a certain way. These two organizations combined their efforts to build a single standard and in December 1986 introduced Standard Generalized Markup Language.

SGML stands for Standard Generalized Markup language. Let's look at each word in SGML to see what it adds to the concept.

Standard - SGML is an internationally recognized standard (ISO 8879).

Generalized - SGML allows documents to be marked up and stored in a neutral format [2]. This neutrality is achieved by using generic identifiers instead of application specific identifiers. The fact that SGML is independent of systems, devices and languages enforces the term generalized.

Markup - Markup is text added to the data of a document to convey information about it and to indicate its structure. The procedure and rules to mark up a document is stated in SGML.

Language - SGML is actually not a language but is a metalanguage. It has syntax but no semantics [3]. It is used to describe a document. A document can be broken into three layers: structure, content and style [4, 5]. SGML separates these three layers and mainly deals with the relationship between structure and content.

SGML is an open standard which is both platform and application independent. SGML files are ASCII text files which can be used on virtually any platform. SGML has introduced innovations that drastically improve the publication process and is a language for content creation that formalizes markup and frees it of any system processing dependencies. Reuse of information across multiple publications by splitting documents into smaller modules enable authors to assemble information in different combinations for various purposes and audiences. Content is structured using a Document Type Definition (DTD) and separation of content from formatting is achieved using a Format Output Specification Instance (FOSI).

Some of the benefits of SGML are as follows:

- Documents can be exchanged with users having different software applications, computer networks and hardware platforms. An SGML document will outlive existing technology and whatever comes along in the future.

- $\quad$ Since content is separated from style using SGML, an author concentrates more on content rather than appearance. The author can also reuse pieces of a document saving the effort needed for recreation.
- Data can be updated easily especially when copies of a publication are located in several places and failure to update all copies of a publication can lead to operational failures.

- Using SGML many applications can access the same set of information. Data can be broken into chunks of information and a chunk may appear in technical manuals, training guides and publications. Updating of a chunk of information ensures that many applications that use the same set of information have the latest update.

- Conversion of documents created using SGML is not needed when hardware or software becomes obsolete. SGML's standard file format always allows availability of information once the document is created.

- $\quad$ Since documents created in SGML are structured it is possible to perform complex searches in a document. Database technology uses fields and records to store information while SGML uses elements such as chapters, sections, titles and paragraphs instead of fields and records. To find all publications in which the first paragraph start with the words "OEM Compliance" is a complex task in paper publications. In SGML this task is made simpler.

- SGML implementation is ideal for aerospace and defense industries since it addresses the following requirements:

- Having huge volumes of data. For example at present Airbus A320 has documentation representing 1.2 gigabytes in 39 different manuals.

- Parts of information appearing in more than one document.

- Information must be accessible across succeeding generations of computer hardware and software.

- Information is considered critical and an important corporate asset.

- Frequently updated and revision to information.

- Linkages to granular levels of a document like words, paragraphs, sections, etc.

- $\quad$ Requiring complex approval processes and sign offs.

- Information coming from different sources and is in different formats.

- Requiring integration of components of information produced by multiple authors.

- Information to be shared among several organizations.

- Integration of components that depend upon external factors like economic or environmental factors.

- Data targeted to different user groups each having specific security classifications. 
- Information can be interchanged across heterogeneous systems regardless of the software application or hardware platform for which it was originally created [6].

- $\quad$ Must be produced in many different formats, such as paper, CDROM, Web, etc.

\section{MODULAR APPROACH}

The publication process initiates with identification of modules that comprise the publication under development. A module is a self-contained unit of data containing text and/or illustration. A technical publication of equipment can be comprised of modules conveying information on its description, operation, assembly, disassembly, cleaning, repair and storage. Each module has metadata associated with it. The metadata specifies information that uniquely identifies it from other modules like

$\begin{array}{ll}- & \text { Module number } \\ \text { - } & \text { Title } \\ \text { - } & \text { Issue number and } \\ \text { - } & \text { Date }\end{array}$

In the Fig. (1) below technical information of a Main Rotor Blade is divided into independent modules like description, operation, assembly, disassembly and cleaning. Each of these modules is an independent file containing text and/or illustration. These files are created using Standard Generalized Markup Language, Document Type Definition, and Formatting Output Specification Instance.

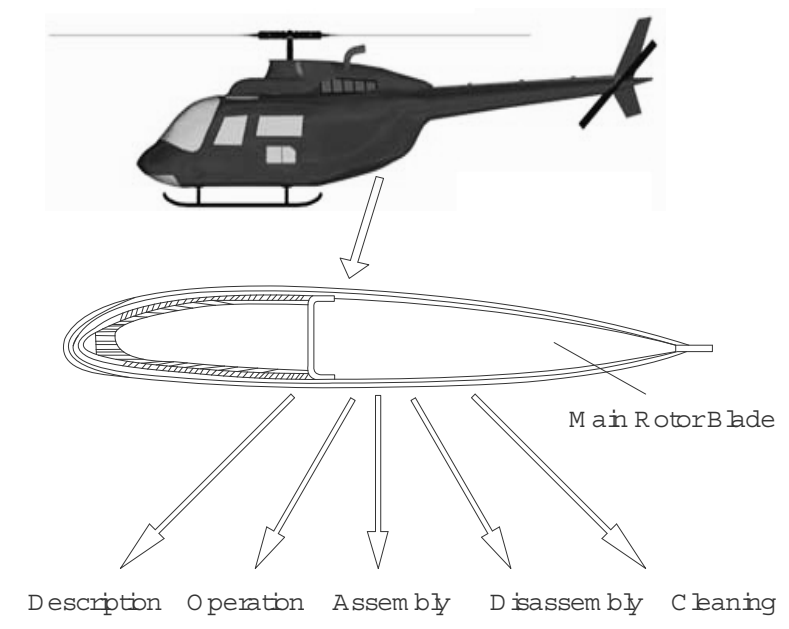

Fig. (1). Main rotor blade modules.

\section{STRUCTURED CONTENT}

In each module, SGML enforces content to be developed in a structured manner. This maintains consistency across publications. The idea of SGML is to structure text by adding explicit structure descriptors [7]. This structured approach is achieved using a Document Type Definition. Since SGML requires explicit and consistent structure, the DTD defined for the documents will impose rules that may not have been considered when the author created the original document [8].
In a Standard Generalized Markup Language module a DTD defines elements allowed, their associated attributes and relationships among elements. An instance is any text created according to the rules dictated by the DTD. These instances are validated with respect to the DTD using compilation software called a Standard Generalized Markup Language parser.

For example an installation module can be defined having the following elements:

- Module Number is a number that uniquely identifies the equipment and its module type.

- Title specifies the equipment name and module name.

- Issue Number shows the issue number.

- $\quad$ Issue date is the date that the module is released and comprises the "day", "month" and "year".

- Preliminary Steps either indicate that no required conditions are to be carried out before starting the procedure or it gives a brief description of the requirements.

- Required Persons identifies persons required to perform the task. It comprises of trades of the persons required (Mechanical, Electrical, Radio, etc.) and skill level of the person (Basic, Intermediate or Advanced).

- $\quad$ Support Equipment shall contain a list of special tools and general test equipment used to carry out the procedure. The list shall contain entries for Part No., Nomenclature and Quantity for each of the tools listed.

- Supplies shall contain a list of consumables used to carry out the procedure. The list shall contain entries for Part No., Nomenclature and Quantity for each of the consumables.

- Spares shall contain a list of replacement parts required to carry out the procedure. The list shall contain entries for Part No., Nomenclature and Quantity for each of the supplies.

- $\quad$ Safety identifies any safety conditions applicable to the task being undertaken. It includes any Warnings, Cautions and Notes that are applicable to the entire procedure. A warning is used to alert the reader to possible hazards, which may cause loss of life, physical injury or ill health. A caution is used to denote a possibility of damage to material but not danger to personnel. A note is used to convey information that is extraneous to the immediate subject of the text.

- Procedural Steps is to tell the reader how to do the task.

- Final Checks is used to identify any additional requirements to be carried out after completion of the module procedure. 
Once the structure of a module is finalized, installation data of all components will follow this structure. Since the data is structured it makes it easier to read and understand. Moreover structured information allows reuse and automatic formatting using a Format Output Specification Instance (FOSI).

\section{DEFINING A DOCUMENT}

A Document Type Definition (DTD) defines the structure of an SGML module. It is recommended when designing the DTD, the user first analyze the type of documents for which the DTD is required because a DTD is constructed so that it includes every element that is common to any given type of document [9]. The DTD functions mainly as a template identifying the type of module - description, operation, assembly, disassembly or cleaning and the order of elements appearing in the module. A DTD that is created can be general enough so that it can apply to all modules of the same type. In other words if a DTD is structured properly it can be applied to most modules of the same type. There will be no need to recreate a DTD each time a user writes an installation module. The original installation DTD can be reused over and over again. It is composed of elements, attributes and entities. A DTD defines the following:

- Elements that are allowable and how often an element may appear.

- $\quad$ Order of elements appearing.

- $\quad$ Attributes and their content type.

- Names of all entities that can be used.

SGML parsers are programs that check if the markup in a document satisfies the rules defined by the DTD. Consider a portion of the installation module structure shown in the below Fig. (2).

The DTD and SGML fragment for this portion is as follows:

SGML DTD

$<$ !ELEMENT partlist - - (part)+>

$<$ !ELEMENT part - - (partno, nomen, qty) $>$

$<$ !ELEMENT (partno, nomen, qty) - - (\#PCDATA) >

SGML Fragment

$<$ partlist $>$

$<$ part $>$

$<$ partno $>1234567<$ partno $>$

$<$ nomen $>$ Aaaa $<$ /nomen $>$

$<$ qty $>444</$ qty $>$

$</$ part $>$

$<$ part $><$ partno $>2345678<$ partno $>$

$<$ nomen $>$ Bbbb $</$ nomen $>$

$<$ qty $>5,555<$ qty $>$

$<$ part $>$

$<$ partno $>3456789<$ partno $>$

$<$ nomen $>$ Cecc $<$ /nomen $>$

$<$ qty $>666,666</$ qty $>$

$</$ part $>$

$<$ partlist $>$

\section{REUSABILITY}

Modularization allows technical publications to be broken up into modules allowing reuse of content instead of recreation. When an author does not find content that already exists, then it is recreated. On the otherhand if the content is found, it is typically copied and pasted into a new document.

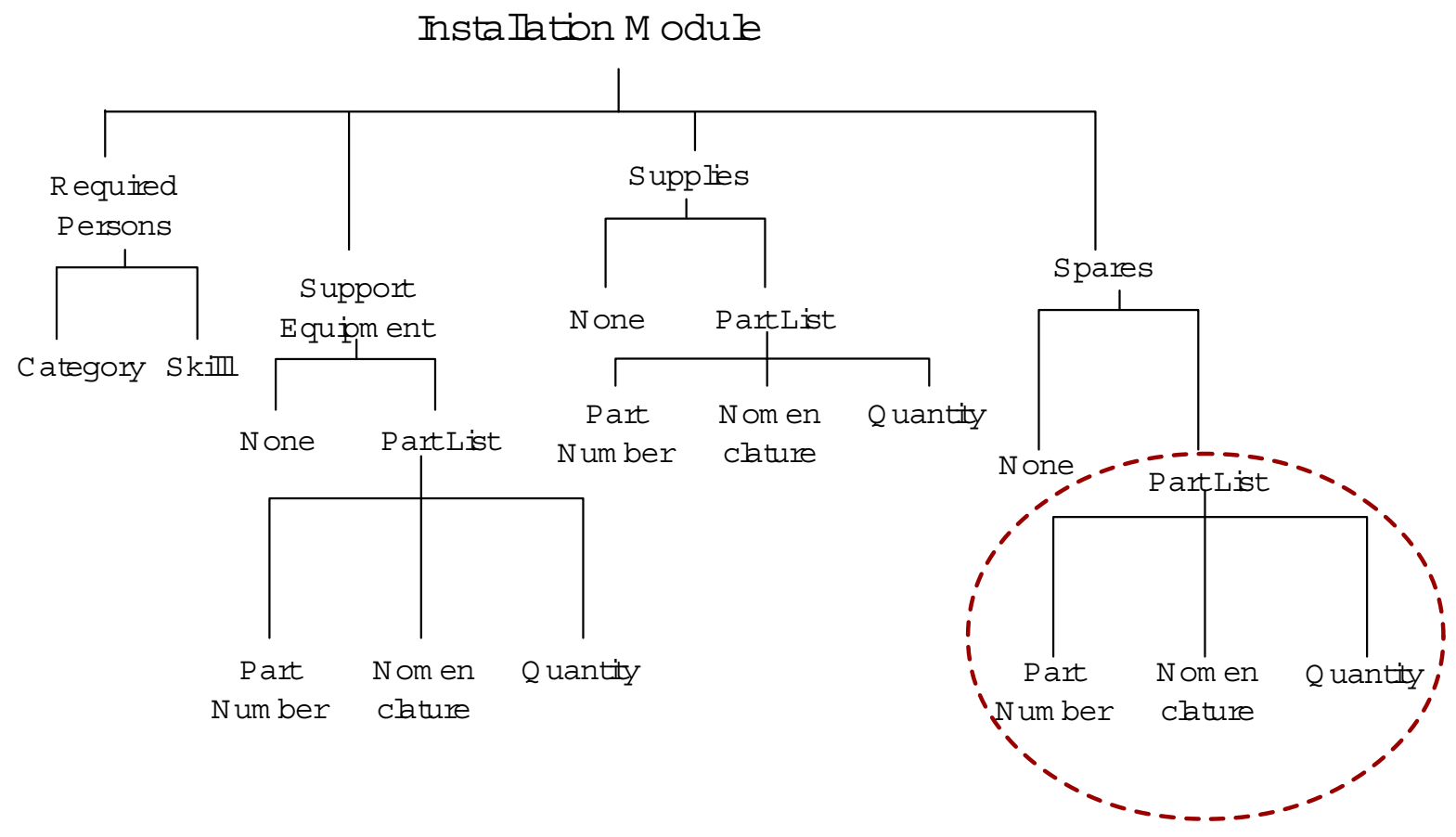

Fig. (2). Portion of installation module structure. 
Both of these approaches result in wastage of effort and time in finding and updating all repeated passages of content. Rewriting instead of reusing also poses a risk of redundant information being inconsistent across documents.

In the Fig. (3) below an installation module created for a component can be used across maintenance, overhaul and repair manuals without recreation and reformatting.

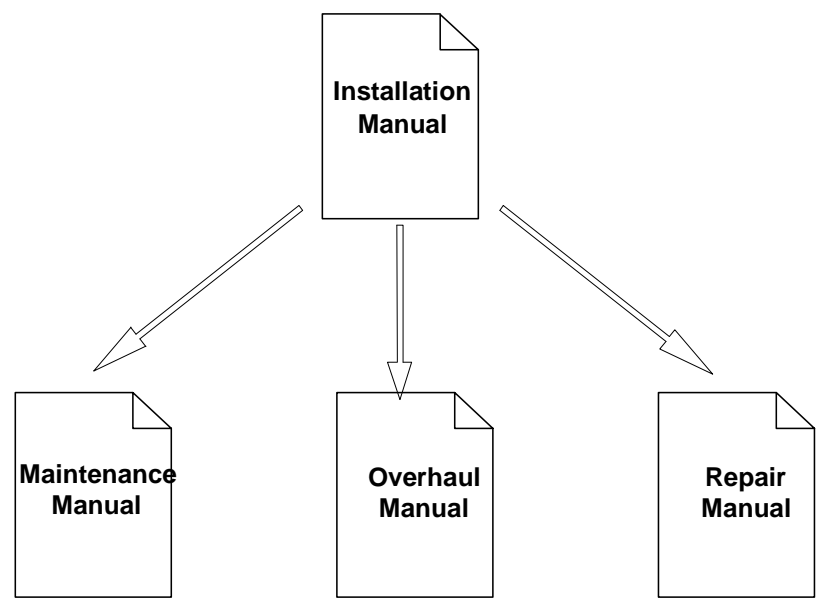

Fig. (3). Installation manual reusability.

\section{ILLUSTRATIONS}

Illustrations also play an important role in the development of data modules. A unique id, title and board number identifies each illustration. A Board Number is used to link the correct illustration to the corresponding SGML illustration element. To add an illustration to an SGML file we must first define a board number for each illustration and link it to the corresponding externally stored illustration file as shown below.

Here the board number (HEL-ROTORSYS-MRB-001) is linked to the illustration file "main-rotor-blade.CG4".

$<$ !DOCTYPE installmod SYSTEM "install.dtd"> [

$<$ !ENTITY HEL-ROTORSYS-MRB-001 SYSTEM "mainrotor-blade.CG4" NDATA FAX> ]>

Once the board number is linked to an illustration file, we can specify in the SGML file where we would like the illustration to appear.

$<$ fig id="F1">

$<$ title $>$ Main Rotor Blade $</$ title $>$

$<$ grap board_no=" HEL-ROTORSYS-MRB-001">

$</$ fig $>$

\section{INDEPENDENT FORMATTING}

Formatting Output Specification Instance (FOSI) is a style sheet language developed to control the formatting of SGML technical data. These FOSI stylesheets are written in SGML to describe the presentation of structured documents. Since the content has been structured using a DTD, the document can be presented in different styles. For each DTD there should be at least one FOSI. However multiple FOSIs for the same DTD can be developed to produce different publishing formats for the same SGML instance.

\section{Examples:}

Each line starts with <eic gi="..."> that contains formatting characteristics of an element defined in the DTD. An "eic" denotes "element in context" and "gi" denotes "generic identifier".

To make the title bold

$<$ eic gi="title">

$<$ charlist $>$

$<$ font weight="bold" $>$

To start a procedure on a new page with text PROCEDURE

$<$ eic gi="proc">

$<$ charlist $>$

$<$ textbrk startpg="1">

$<$ puttext="PROCEDURE">

To indent paragraphs appearing in a caution by 10 points

$<$ eic gi="para" context="caution" $>$

$<$ charlist $>$

$<$ indent leftindent $=" 10 \mathrm{pt} ">$

To make paragraphs appearing in a warning as bold

$<$ eic gi="para" context="warning">

$<$ charlist $>$

$<$ font weight="bold" $>$

\section{INTEGRATION OF SGML AND WORLD WIDE WEB}

Large audiences can be reached out to information that is time critical and changes rapidly using the World Wide Web (WWW). This helps to reduce high costs associated with reproduction and distribution of information in hard copy format. SGML is playing an important role in information available on the Internet. The World Wide Web is a hypertext system based on SGML. Hypertext Markup Language (HTML) based on SGML has its own Document Type Definition (DTD) and also relies on tags. These tags are read in the HTML file and displayed on the computer screen of the user using a WWW browser.

All WWW browsers may not be capable of reading SGML documents. Since the documents on the WWW are in HTML format, SGML documents can be converted to HTML using a parser that meets the requirements of a specific browser. This conversion would ensure that the document conforms to the HTML DTD for use on the WWW.

In some cases SGML documents may be large in size with respect to the number of pages of information held in an SGML file. WWW browsers work best with documents having few pages. These SGML documents can be broken down further 
and linked to enable users to access components they desire without having to access a large document.

WWW will facilitate universal access to information that is unrestricted to personnel on a daily basis. Distributing information via the WWW requires information to be published in only one place and once published this information is available to any of the million web users. A central repository for electronic document distribution simplifies the updating procedure and version control. Old versions are replaced with new releases and any one accessing these documents get the latest information. Users can also query documents and search for information or related topics.

\section{WHO USES SGML}

\section{Her Majesty's Stationery Office}

Her Majesty's Stationery Office (HMSO) is the UK Government publisher and is responsible for printing statutes, as they are passed by Parliament. From 1987 statutes have been prepared using SGML with the intention that every new statute will appear both in printed and electronic form. All versions of legislation will be stored with cross-referencing achieved using SGML.

\section{The Commission of the European Communities}

A system called FORMEX (Formalized Exchange of Electronic Documents) has been developed by the Official Publications Office of the European Communities to facilitate in the production of the publications of the Commission along with archiving of these documents in electronic form. SGML along with suitable DTDs was chosen for developing various documents.

\section{Oxford University Press}

SGML has been used in the production of electronic version of the Oxford English Dictionary. The 12 volumes and supplement (4 volumes) comprising of 21 thousand pages have been coded into SGML. Using SGML all future editions will be maintained along with different variants of the dictionary.

\section{McGraw-Hill}

The Encyclopedia of Science and Technology of McGrawHill was prepared using SGML. This made it possible to be produced both in printed and electronic forms (CD-ROM). This textual material is also now available in an on-line public database.

\section{Hewlett-Packard}

More than fifty writing departments worldwide are involved in the production of documentation for Hewlett-Packard computers, software and instruments and exchange of information in electronic form between departments is a requirement. SGML has been used to address this requirement and a parser called MARKUP that is developed in-house is being used.

\section{Ontario Hydro (Canada's largest utility)}

SGML was chosen as a technology to convert 20,000 pages of documentation comprising of 11,000 pages of operator's manuals, 8,500 pages of training manuals, and 300 pages of schematics. This has been used by maintenance technicians in troubleshooting and printing portions of manuals associated with the problem.

\section{COMPARISON BETWEEN TRADITIONAL PUBLISHING AND SGML}

In Table 1 comparison between using traditional publishing tools and SGML for creation of documentation is shown.

Table 1. Comparison Between Traditional Publishing and SGML

\begin{tabular}{|c|c|c|}
\hline $\begin{array}{c}\text { Publishing } \\
\text { System Essentials }\end{array}$ & $\begin{array}{c}\text { Traditional } \\
\text { Publishing System }\end{array}$ & $\begin{array}{c}\text { Standard Generalized } \\
\text { Markup Language (SGML) }\end{array}$ \\
\hline Modularization & $\begin{array}{l}\text { Entire document } \\
\text { treated as a single } \\
\text { module. }\end{array}$ & $\begin{array}{l}\text { SGML allows a document to } \\
\text { be broken up into modules } \\
\text { allowing reusability. }\end{array}$ \\
\hline $\begin{array}{l}\text { Structured } \\
\text { Content }\end{array}$ & $\begin{array}{l}\text { Content is not } \\
\text { structured across } \\
\text { similar types of } \\
\text { publications resulting } \\
\text { in no consistency. }\end{array}$ & $\begin{array}{l}\text { SGML enforces content to be } \\
\text { developed in a structured } \\
\text { manner maintaining } \\
\text { consistency across } \\
\text { publications. This structured } \\
\text { approach is achieved using a } \\
\text { Document Type Definition. }\end{array}$ \\
\hline $\begin{array}{l}\text { Independent } \\
\text { Formatting }\end{array}$ & $\begin{array}{l}\text { Each time a document } \\
\text { is created or updated } \\
\text { formatting has to be } \\
\text { applied manually. }\end{array}$ & $\begin{array}{l}\text { Separation of content from } \\
\text { formatting is achieved using } \\
\text { Format Output Specification } \\
\text { Instances (FOSIs). Content can } \\
\text { be constantly updated without } \\
\text { the need to worry about } \\
\text { changes in formatting. }\end{array}$ \\
\hline $\begin{array}{l}\text { Addressing } \\
\text { different media } \\
\text { like print, web, } \\
\text { etc. }\end{array}$ & $\begin{array}{l}\text { Preparing documents } \\
\text { for print or web } \\
\text { requires complete } \\
\text { reformatting. }\end{array}$ & $\begin{array}{l}\text { Since the content has been } \\
\text { structured using a DTD, the } \\
\text { document can be presented in } \\
\text { different styles using different } \\
\text { FOSIs. }\end{array}$ \\
\hline
\end{tabular}

\section{BENEFITS OF USING SGML}

Many experts in the field of SGML [5, 9-11] note that there are several benefits of using SGML. Based on a study from journals, publications and the World Wide Web, most common benefits of SGML were

- $\quad$ Content being separated from style

- $\quad$ Structured data

- Hardware and software independence

- $\quad$ Reusability of data

- $\quad$ SGML's well-defined structure makes it possible to perform complex searches in documents [11].

- Sharing of components of information

- $\quad$ Quick updating of information and

- $\quad$ Publishing as different output formats

XIII. USE OF SGML IN GOVERNMENT AND COMMERCIAL ENTERPRISES

Government and Commercial enterprises are already in the process of migrating from paper to electronic publishing. Some of the commercial enterprises are listed below 
- Her Majesty's Stationery Office: Statutes passed by Parliament

- Commission of the European Communities: Publications of the Commission

- Hewlett-Packard: Documentation for computers, software and instruments

- Oxford University Press: English Dictionary

- McGraw-Hill: Encyclopedia of Science and Technology

- $\quad$ Ontario Hydro: Operator's manuals, training manuals, and schematics

- $\quad$ Shell UK Exploration \& Production: Safety Manuals

- $\quad$ Silicon Graphics - IRIS InSight: Online documentation

\section{SGML EDITORS}

Creation of SGML documents conforming to a Document Type Definition (DTD) requires both an SGML editor and a parser. The editor is used to enter information and insert markup into the document and the parser checks the markup conforms to the rules specified in the DTD.

Following are the popular SGML Editors are listed below

- $\quad$ SoftQuad's Author/Editor

- Arbortext's ADEPT editor

- GRIF's SGML editor

- InContext

- TimeLux's EditTime

James Clark's SP Parser is a popular SGML parser.

\section{MANAGEMENT OF TECHNICAL PUBLICATIONS OF A FIGHTER AIRCRAFT}

\section{Objectives}

The technical publications department of a fighter aircraft manufacturer was faced with the responsibility of maintaining the technical publications of a fighter aircraft. These technical publications at present were being composed in MS-Word with illustrations in AutoCAD.

\section{Implementation}

The technical publications department decided to carry out a comparison between a traditional publishing tool like Microsoft Word and Standard Generalized Markup Language to manage their publication information. The exercise comprise of conversion of the following publications from hardcopy to Microsoft Word and Standard Generalized Markup Language

- $\quad$ Flight Manual (700 pages) - Contains a description and operation of each system of the aircraft, recommended procedures for normal ground and air operations, recommended procedures in case of emergencies and malfunctions and performance information necessary for pre-flight and in-flight mission planning.
- $\quad$ Flight Reference Cards (125 pages) - This publication contains a checklist that is used as a pilot's reference aid.

SGML was used to create data modules for description, operation, normal operating procedures, emergency operating procedures, performance data and operating limitations that were shared between these publications as shown in Fig. (4) below.

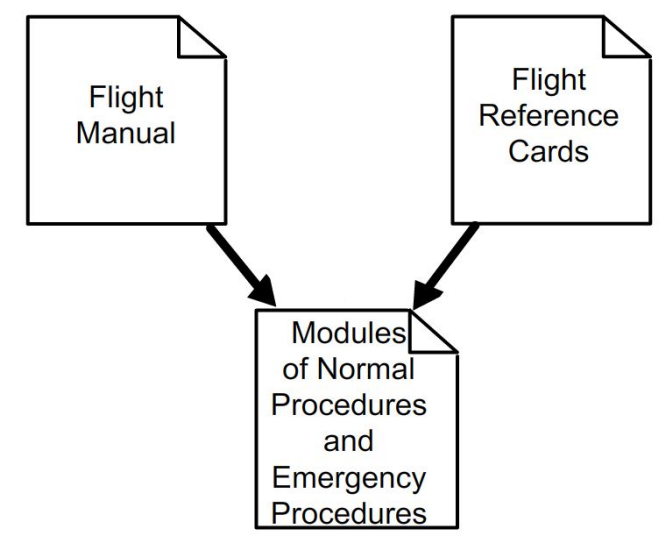

Fig. (4). Reusability between flight manual and flight reference cards.

Format Output Specification Instances (FOSIs) were created for these publications in both print view and electronic view.

In Table 2 comparison between using SGML and Microsoft Word for creation of Flight Manual and Flight Reference Cards comprising of 825 pages is shown.

Table 2. Comparison Between SGML and Microsoft Word

\begin{tabular}{|l|c|c|}
\hline & $\begin{array}{c}\text { Standard Generalized Markup } \\
\text { Language }\end{array}$ & $\begin{array}{c}\text { Microsoft } \\
\text { Word }\end{array}$ \\
\hline \hline $\begin{array}{l}\text { Effort for initial } \\
\text { composition of } 825 \\
\text { pages }\end{array}$ & 127 man-hours (15\% reusability) & 236 man-hours \\
\hline $\begin{array}{l}\text { Effort for reformatting } \\
\text { and finalization of } 825 \\
\text { pages }\end{array}$ & 27 man-hours & 142 man-hours \\
\hline $\begin{array}{l}\text { Schedule of completion } \\
\text { and delivery of } 825 \\
\text { pages }\end{array}$ & 20 man-days & 58 man-days \\
\hline Defect Rate & 1 in 554 pages & 1 in 47 pages \\
\hline
\end{tabular}

Following were the metrics collected:

\section{Project Outcome}

The production improvements and cost savings achieved were impressive. After implementing this innovative solution, following were the results:

- $\quad$ Cut redundant editing by $81.2 \%$

- $\quad$ Reduced production time by $65.5 \%$

- $\quad$ Increased output by $85.8 \%$ 
- $\quad$ Lowered error rates from one every 47 pages to one every 554 pages

\section{MANAGEMENT OF TECHNICAL PUBLICAT- IONS OF A CIVIL HELICOPTER}

\section{Objectives}

The technical publications department of a helicopter production company was faced with the responsibility of maintaining the technical publications of a civil helicopter. These technical publications at present were in hardcopy supplied by the helicopter manufacturer.

\section{Implementation}

The technical publications department decided to carry out a comparison between a traditional publishing tool like Microsoft Word and Standard Generalized Markup Language to manage their publication information. The exercise comprise of conversion of the following thee publications from hardcopy to Microsoft Word and Standard Generalized Markup Language

- Maintenance Manual (1400 pages) -This publication explains the description and operation of each helicopter system, its components and their location. Procedures for installation, removal, cleaning, repair, inspection and testing of these components are also included.

- Illustrated Parts Catalogue (1100 pages) - This publication contains all the helicopter assemblies and their parts. Each part is identified with a part number and nomenclature. The quantity of the part required for the assembly as well as the vendor of the part is also included.

- Description and Operation Manual (550 pages) - The description and operation of each helicopter system, its components and their location are explained in this publication.

Using SGML, the technical publications department divided their data into data modules like description, operation, installation, removal, cleaning, repair, inspection and testing. These data modules were shared between the maintenance manual and description and operation manual as shown in Fig. (5) below.

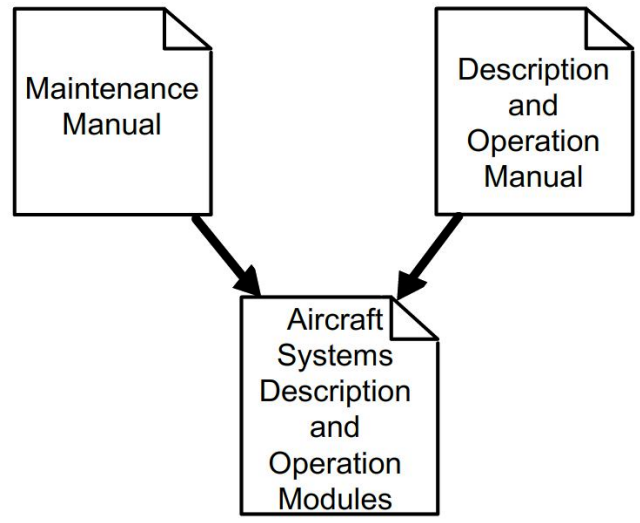

Fig. (5). Reusability between maintenance manual and description and operation manual.
Format Output Specification Instances (FOSIs) were created to allow the technical publications department to have different organizational views of the same information. The print view organizes information by document structure while the electronic view arranges information hierarchically by aircraft system. The actual content modules are the same in each view but the user sees it configured in two different ways.

In Table 3 comparison between using SGML and Microsoft Word for creation of Maintenance Manual, Illustrated Parts Catalogue and Description and Operation Manual comprising of 3050 pages is shown.

Table 3. Comparison between SGML and Microsoft Word

\begin{tabular}{|l|c|c|}
\hline & $\begin{array}{c}\text { Standard Generalized } \\
\text { Markup Language }\end{array}$ & Microsoft Word \\
\hline \hline $\begin{array}{l}\text { Effort for initial } \\
\text { composition of } 3050 \text { pages } \\
\text { from hardcopy }\end{array}$ & $\begin{array}{c}417 \text { man-hours } \\
(18 \% \text { reusability })\end{array}$ & 763 man-hours \\
\hline $\begin{array}{l}\text { Effort for reformatting and } \\
\text { finalization of } 3050 \text { pages }\end{array}$ & 40 man-hours & 458 man-hours \\
\hline $\begin{array}{l}\text { Schedule of completion } \\
\text { and delivery of } 3050 \text { pages }\end{array}$ & 42 man-days & 114 man-days \\
\hline Defect Rate & 1 in 667 pages & 1 in 33 pages \\
\hline
\end{tabular}

\section{Project Outcome}

The production improvements and cost savings achieved were impressive. After implementing this innovative solution, following were the results:

- $\quad$ Cut redundant editing by $91.2 \%$

- $\quad$ Reduced production time by $63.1 \%$

- Increased output by $82.9 \%$

- Lowered error rates from one every 33 pages to one every 667 pages

\section{CONCLUSION}

An analysis of the metrics collected during the implementation of SGML in technical publications of a civil helicopter and fighter aircraft demonstrates the following benefits

- Cut redundant editing by $80 \%$ or more

- $\quad$ Reduced production time by $60 \%$ or more

- Increased output by $40 \%$ or more and

- $\quad$ Lowered error rates to one every 400 or more pages

On the basis analysis of the information gathered there is an indication that SGML is a powerful tool that Aerospace and Defense publication departments need to use to improve the efficiency and effectiveness of its publication process. SGML reduces the time taken to publish technical publications, standardize document structure, eliminate the storage of paper-based documents, provide latest accurate 
information and permit its availability electronically on personal computers.

The documentation life cycle (creating, distributing, retrieving and reusing) has been constantly affected by new generations of hardware and software. SGML also solves a problem most people do not know they have. Not until an organization reaches a crisis - the inability to deal with backlog, the high cost of converting to a new system, or the failure to keep information accurate and up-to-date- does the organization realize there is a problem [12]. SGML has overcome these hurdles with benefits in terms of portability of information, reusability, availability and an increase in productivity.

SGML is also playing an important role in availability of information through the World Wide Web. Publishing information on the World Wide Web provides customers with access to latest information around the clock. This reduces hurdles faced with hardcopy updating and distribution. Retrieval of information is done in a matter of seconds as compared to the days when a hardcopy had to be requested from the publication distribution office. Search and retrieval of information is achieved through links to various documents that are interrelated. Aerospace and Defense publications can be linked to each other and to other documents such as forms that are referenced by them. Linkages of documents enable accessing of publications with a supplement very simple. Since documents are linked the supplemented information can appear in a requested publication without the need of accessing two separate documents.
Once a decision is made to adopt SGML, commercially available editors and parsers are available for conversion and authoring of documents to SGML. An abundance of information on SGML products and tools are available on the World Wide Web.

\section{REFERENCES}

[1] Burnard, "What is SGML and how does it help?, XML Cover Pages, 1991. [Online] Available: http://xml.coverpages.org/edw 25.html. [Accessed $10 \mathrm{Feb} 2009$ ].

[2] Smith, "SGML and related standards: document description and processing languages", Ellis Horwood Series in Computers and their Applications, vol. 1, p. 14, 1992.

[3] Heimburger, "Introduction to Standard Generalized Markup Language (SGML)", Microcomputers for Information Management, vol. 11, no. 4, pp. 239-260, 1994.

[4] H. Wright, "SGML frees information", Byte, vol. 17, no. 6, pp 279-286, 1992.

[5] E. Gilmore, "Introducing today's SGML", Technical Communication, vol. 40, no. 2, pp. 210-218, 1993.

[6] L. Turner, "What every CIO should know about SGML", CALS/Enterprise Integration Journal, vol. 106, pp. 53-57, 1994.

[7] McCormick, "SGML document introducing you to SGML", Cloud 9 , 1999. [Online] Available: http://www.cloud9.net/ bradmcc/What IsSGML.html. [Accessed Mar. 5, 2009].

[8] Gross, "Getting your data into SGML", Technical Communication, vol. 40, no. 2, pp. 219-225, 1993.

[9] Stern, "SGML documents: a better system for communicating knowledge", Special Libraries, vol. 86, no.2, pp. 117-124, 1995.

[10] M. Wood, "So what is SGML?", Journal of Systems Management, vol. 46, no.5, pp. 24-29, 1995.

[11] Lunemann, "Nuts and bolts of SGML", Technical Communication, vol. 42, no. 2, pp. 344-345, 1993.

[12] Ensign, "SGML by evolution", Technical Communication, vol. 40, no. 3, pp. 387-393, 1993. 